\title{
Охотничья лексика в языковой картине мира народов Саяно-Алтая (на материале тувинского, тофаларского, алтайского и хакасского языков)
}

\author{
Шенне В. Дамбаа, Надежда Д. Сувандии \\ Тувинский государственный университет, Российская Федерация
}
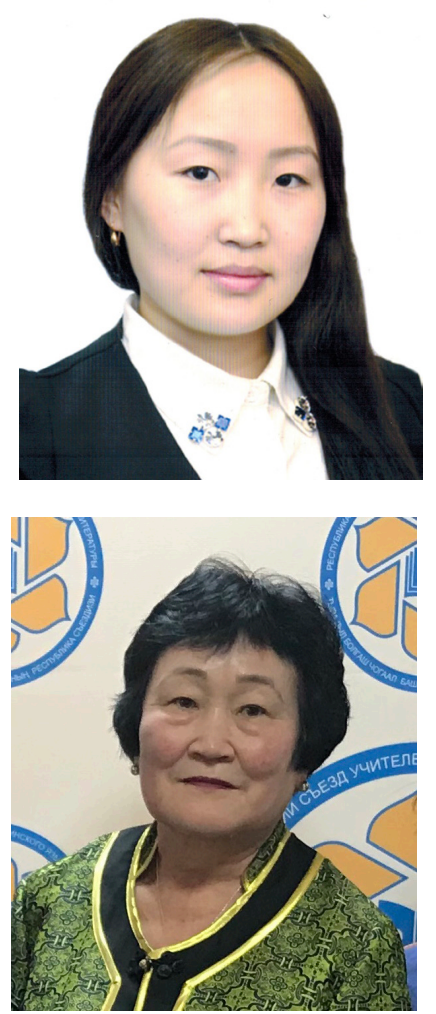

В статье представлены результаты сравнительного анализа лексики охоты в ряде тюркских языков народов Саяно-Алтая: тувинского, алтайского, хакасского и тофаларского. Анализ выполнен для определения общих и отличительных особенностей. Охота - один из древних видов деятельности народов этого региона, который потерял былую значимость. Вслед за этим уходит и лексика, фиксация которой важна для задач сохранения культуры.

В ходе исследования выявлено четыре основных лексико-семантических групп: названия парнокопытных диких животных, хищников, мелких зверей и птиц. В выделенных лексико-семантических группах имеются общие лексемы, как общетюркское

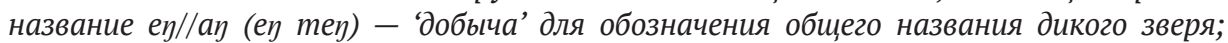
наименования птицы куш тув., алт., хус хак. В лексико-семантической группе «Названия хищных животных» встречаются большое количество эвфемизмов, заменяющих слова-табу, которые по этикету народов Саяно-Алтая являются священными запретами.

Ключевые слова: тюркские языки; тувинский язык; хакасский язык; алтайский язык; тофаларский язык; специальная лексика; охотничья лексика; лексико-семантическая группа; Саяно-Алтай

Подготовлено при финансовой поддержке Российского фонда фундаментальных исследований в рамках научного проекта «Трансформационные процессы в ономастике народов Центральной Азии: история и современность (на примере Тувы, Тофаларии, Калмыкии и Монголии)» (грант No 19-012-00073).

\section{Для цитирования:}

Дамбаа Ш. В., Сувандии Н. Д. Охотничья лексика в языковой картине мира народов Саяно-Алтая (на материале тувинского, тофаларского, алтайского и хакасского языков) // Новые исследования Тувы. 2021, № 4. С. 172-185. DOI: https://www.doi.org/10.25178/nit.2021.4.13

Дамбаа Шенне Вадимовна - ассистент кафедры тувинской филологии и общего языкознания Тувинского государственного университета. Адрес: 667000, Россия, г. Кызыл, ул. Ленина, д. 36. Тел.: +7 (923) 385-22-42. Эл. адрес: shenne2242@mail.ru Сувандии Надежда Дарыевна - кандидат филологических наук, декан филологического факультета Тувинского государственного университета. Адрес: 667004, Россия, г. Кызыл, ул. Педагогическая, д. 13. Тел.: +7 (923) 268-93-69. Эл. адрес: suvandiin@mail.ru

DAMBAA, Shenne Vadimovna, Assistant, Department of Tuvan Philology and General Linguistics, Tuvan State University. Postal address: 36 Lenina St., 667000, Russia, Kyzyl. Tel.: +7 (923) 385-22-42. E-mail: shenne2242@mail.ru 


\title{
Hunting vocabulary in the linguistic world picture of the Sayan-Altai peoples: The case of Tuvan, Tofalar, Altai and Khakass languages
}

\author{
Shenne V. Dambaa, Nadezhda D. Suvandii \\ Tuvan State University, Russian Federation
}

The article presents the outcome of a comparative study of hunting vocabulary in a number of Turkic languages of the peoples living in the Sayan-Altai region: Tuvans, Tofalars, the Altai and the Khakass. The study focused on the generalities and particularities of linguistic picture of hunting as one of the old pursuits of the people of the region, which by now has lost its past importance. Following the demise of the hunting is the vocabulary, which must be recorded in order to help preserve their cultures.

The study showed that there are four lexico-semantic groups dealing, respectively, with the names for wild ungulates, predators, small

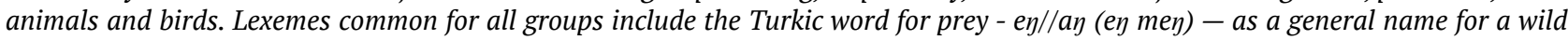
animal, and for the bird, 'kush' (Tuvan and Altai 'hus hak'). The lexico-semantic group of "predator names" includes a large number of euphemisms to replace taboo words which the speech etiquette of the Sayan-Altai peoples prohibits to mention openly.

Keywords: Turkic languages; Tuvan language; Khakass language; Altai language; Tofalar language; specialized vocabulary; hunting vocabulary; lexico-semantic group; Sayan-Altai

\begin{abstract}
Financing
The article has been prepared with financial support from the Russian Foundation for Basic Research as part of the research project "Transformational processes in the onomastics of the peoples of Central Asia: history and contemporary state (the cases of Tuva, Tofalaria, Kalmykia, Mongolia)" (Grant No. 19-012-00073).
\end{abstract}

For citation:
Damba Sh. V. and Suvandii N. D. Okhotnich'ia leksika v iazykovoi kartine mira narodov Saiano-Altaia (na materiale
tuvinskogo, tofalarskogo, altaiskogo i khakasskogo iazykov) [Hunting vocabulary in the linguistic world picture of
the Sayan-Altai peoples: The case of Tuvan, Tofalar, Altai and Khakass languages]. New Research of Tuva, 2021, no. 4,
pp. 172-185. (In Russ.). DOI: https://www.doi.org/10.25178/nit.2021.4.13

\section{Введение}

Охота является одним из основных видов древнейших традиционных занятий человечества и каждый народ имеет свои традиции охоты, а соответственно и охотничью лексику. Для тюркских народов охота также составляла важную часть традиционных промыслов, что нашло отражение в языке. Об этом свидетельствуют исторические и этнографические материалы ученых (Катанов, 1903; Щербак, 1961; Потапов, 1969; Мусаев, 1975; Рассадин, 1971; Сравнительно-историческая ..., 1997 и др.)

Саяно-Алтай - территория, на которой с древнейших времен соприкасались тюркские, самодийские, кетские, тунгусо-маньчжурские и монгольские племена и их культуры. Поэтому они имеют много общих традиций хозяйственной культуры. Их изучение представляет большой научный интерес и актуальность в свете трансформации культур.

Несмотря на изменения образа жизни современных людей, лексика охоты не утратила своей функциональной активности в речевом пространстве народов Саяно-Алтая, особенно названия диких животных и птиц. В настоящее время есть немало любителей охоты, в свободное от работы время которые проводят в тайге, причем для них это является одним их хобби - отдых на природе. 
Вопросы этногенеза и глоттогенеза ${ }^{1}$ указанных выше народов можно решить, лишь комплексно используя данные археологических, исторических, этнографических, лингвистических, фольклористических и антропологических исследований. К сожалению, не все народы Саяно-Алтайского нагорья изучены во всех этих аспектах в одинаковой мере (Рассадин, 2000: 5).

Цель настоящей работы - систематизировать и сравнить названия диких животных и птиц в тувинском, хакасском, алтайском и тофаларском языках для определения общих и отличительных особенностей. Материалом исследования послужили полевые материалы, собранные авторами в 2013-2021 гг. на территории Республики Тыва от жителей разных районов. Всего было опрошено более 25 человек, занимающихся охотничьим промыслом в возрасте от 20 до 85 лет. Также лексические единицы из тувинско-русского (Тувинско-русский ..., 1968), алтайско-русского (Алтайско-русский ..., 2018), русско-алтайского (Русско-алтайский ..., 1964), хакасско-русского (Хакасско-русский ..., 1953), русско-хакасского (Бутанаев, 2011) и тофаларско-русского (Рассадин, 2005) словарей.

В работе названия диких животных и птиц подразделены на следующие лексико-семантические группы (далее - ЛСГ): копытные дикие животные, хищные животные, мелкие звери, птицы.

\section{Охота как древний род занятий тюркских народов Саяно-Алтая}

Охотой тюркские народы занимались с древних времен и в настоящее время данный вид деятельности все еще функционирует, хотя и в ограниченном объеме. Охотничья лексика нашла свое отражение в тюркском языкознании. Так, А. М. Щербак в сравнительно-историческом аспекте провел изучение лексики отдельных семантических групп домашних и диких животных (Щербак, 1961). Названия диких животных в семантическом и этимологическом аспектах анализируются в монографии М. К. Мусаева, в ней также определяются ареалы их употребления (Мусаев, 1975: 52-158).

В фундаментальном труде тюркологов Э. Р. Тенишева, Г. Ф. Благовой, И. Г. Добродомова, А. В. Дыбо, И. В. Кормушина, Л. С. Левитской, О. А. Мудрака, К. М. Мусаева, представляющих урало-алтайский сектор Института языкознания Российской академии наук, «Сравнительно-историческая грамматика тюркских языков. Лексика» содержится краткая сводка лексического состава пратюркского языка, которая охватывает все важнейшие стороны жизни хозяйства носителей пратюркских диалектов, а также окружающей их природы, среди которых имеется и названия диких животных и птиц (Сравнительно-историческая ..., 1997: 640-649).

Тувинский язык. На рубеже XIX-XX в. Н. Ф. Катанов в своей фундаментальной грамматике тувинского языка впервые привел краткие сведения о занятиях охотой тувинцев (Катанов, 1903).

Следующая работа по интересующей нас теме была опубликована уже через полвека. В монографии С. И. Вайнштейна рассматривается основное занятие тувинцев-тоджинцев - охота (Вайнштейн, 1961). Тувинцы-тоджинцы - особая этническая группа, проживающая на северо-восточной части Республики Тыва, в отличие от жителей других районов республики, занимаются не только оленеводством, но и охотничьей деятельностью, которая остается одним из основных и по настоящее время. В диалекте тоджинцев сохранились этнографические диалектизмы, характеризующие основное занятие коренного малочисленного народа (охота и оленеводство).

Традиционный быт тувинцев в своей работе описал Л. П. Потапов (Потапов, 1969), где охотничье дело тувинцев характеризует как один из видов хозяйственной деятельности народа.

Позже данная тема заинтересовала и ученых-тувинцев. В работе тувинского диалектолога З. Б. Чадамба проведено изучение тоджинского диалекта, одного из специфичных в тувинском языке, носители которых издавна занимались охотничьим промыслом (Чадамба, 1974). В научно-популярной работе исследователя традиционных мужских занятий В. К. Даржа описываются различные виды охоты, орудий охотника, также даются названия диких животных (Даржа, 2009). В. С. Салчак, Б. Баярсайхан, Б. Б. Монгуш в брошюре «Тыва аңныыр ажыл-агыйының дугайында чамдык медээлер» («Некоторые сведения о тувинской охотничьей деятельности») описывают характеристику дикого животного и птицы, когда и как охотиться на того или иного дикого зверя или птицу (Салчак, Монгуш, Баярсайхан

\footnotetext{
${ }^{1}$ Глоттогенез (от греч. glotta - язык и genesis - происхождение) - процесс становления человеческого естественного звукового языка, отличного от других систем языков.
} 
2010). Немало научных работ выпустила одна из соавторов статьи Н. Д. Сувандии, в которых описывается лексика охоты в разных диалектах тувинского языка, в том числе и тоджинского. Автором проводились исследования охотничьих традиций и обычаев, табу и эвфемизмов в тувинском языке (Сувандии, 2013, 2016; Сувандии, Куулар, 2015).

Хакасский язык. Изучение хакасского языка началось, как и большинство тюркских языков, в XVIII в. Г. Ф. Мессершмидтом, Г. Ф. Миллером, П. С. Палласом, В. В. Радловым, Н. Ф. Катановым и др. (см.: Боргояков, 1981). Лексике охоты и рыболовства в хакасском языке и его диалектах посвящена диссертационная работа В. А. Боргоякова, в которой автор подробно описывает лексику промысловой фауны, названия видов охоты, орудий и устройств. Также приводит сведения об обрядах и поверьях хакасов (Боргояков, 2011). О некоторых сведениях охотничьей деятельности хакасов писал этнограф К. М. Патачаков. Он отметил, что охотничий промысел играл значительную роль и в хозяйстве хакасов с давних времен (Патачаков, 1958: 25).

Алтайский язык. Основу хозяйства алтайцев в древности составлял охотничий промысел, который освещается в работах Н. П. Дыренковой (Дыренкова, 1949), в публикациях Л. П. Потапова (Потапов, 1929, 1935, 1949, 1953, 2001), в исследованиях Ф. А. Сатлаева (Сатлаев, 1969, 1974). Исследователь алтайского языка Н. А. Яимова рассматривает в своей работе табуированные наименования диких зверей (Яимова, 1985). Некоторые ученые утверждают, что данный вид занятия у алтайцев в прежних традиционных видах в настоящее время, к сожалению, не сохранился (Назаров, 2008: 128).

Тофаларский язык. Первым, кто описал тофаларский язык, считается М. Кастрен, посетивший Восточные Саяны в 1849 году (Castren, 1857). Продолжили изучение языка и культуры народа Н. Ф. Катанов (Катанов, 1903), в более позднее время Н. П. Дыренкова (Дыренкова, 1963) и др. Одним из основных исследователей языка и культуры тофаларов, описавшим охотничью лексику, является В. И. Рассадин (Рассадин, 1971, 2000, 2013, 2014). Он выделяет, что охота для тофаларов издавна являлась одним из главных источников существования, поэтому различные промысловые животные играли важную роль в их жизни (Рассадин, 1971: 140).

Таким образом, филологических исследований по отдельным языкам сделано достаточно много. Но вот сравнительных исследований почти не было. Мы можем назвать лишь публикации Е. М. Куулар, которая сделала сравнение половозрастных наименований копытных диких животных в тувинском и хакасском языках (Куулар, 2018), а также А. Д. Каксина, в которой провел сравнительный анализ табу и подставных названий в хантыйском и хакасском языках и отметил, что табуированию подвергаются названия диких животных (Каксин, 2016). Это обуславливает новизну нашего исследования.

\section{Наименования парнокопытных диких животных}

В древние времена копытные дикие животные были одним из основных объектов охоты. Данный промысел оказывал большую помощь для содержания семьи мужскому населению тюркских народов. Так как мясо крупных копытных зверей значительно поддерживали питание в зимнее время, их шкуры обрабатывались и шли на приготовление одежды и обуви, на изготовление ремней и некоторых предметов домашнего обихода (Потапов, 1969: 87). От сезонной охоты на парнокопытных животных охотники всегда получали доходы (продажей мяса дичи и рогов). В настоящее время в Туве, особенно в отдаленном Тоджинском районе, имеются охотники-оленеводы, которые зарабатывают данной деятельностью себе на жизнь и кормят свои семьи, проживающие вдали от районного центра в труднодоступных стойбищах оленеводов.

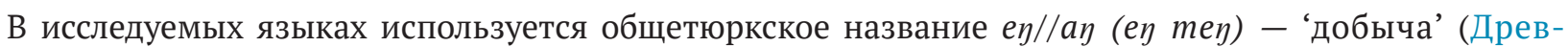
нетюркский словарь, 1969: 174) для обозначения общего названия дикого зверя: тув. ањ (Тувинско-русский ..., 1968: 61), хак. аң (Хакасско-русский ..., 1953: 27), алт. ан (Алтайско-русский ..., 2018 : 72), тоф. ан (Рассадин, 2005: 15).

Парнокопытных диких животных в тувинском языке определяют следующими лексемами: тув. дуюглуг черлик дириг амытаннар - букв. 'копытные дикие животные’ (Толковый словарь ... , 2003: 520), тодж. улуг аңнар - букв. ‘большие звери’. В тофаларском языке зафиксировано смежное название с тоджинским диалектом - тоф. улуг-ан (Рассадин, 2005: 103) в значении ‘большой зверь'. Помимо основных наименований, есть и половозрастные названия диких животных: 


\begin{tabular}{|c|c|c|c|c|}
\hline $\begin{array}{c}\text { Термины на русском } \\
\text { языке }\end{array}$ & Тувинский язык & Хакасский язык & Алтайский язык & Тофаларский язык \\
\hline марал (самец) & CblblH & СыblH & Сыгын & CblblH \\
\hline $\begin{array}{c}\text { маралуха (самка } \\
\text { марала) }\end{array}$ & мыйгак & муйғах & мыйгак & мыйғақ \\
\hline большой марал & чөлеге & - & - & чөлөгө \\
\hline самка марала & сарадак & сарадах & сарадак & - \\
\hline косуля (самка) & элик & илік & элик & элік \\
\hline самец косули & хүлбүс & кёлбӥс & куран & hүлбүс \\
\hline косуленок & анай & оглах & кийик & авнһай-аң \\
\hline лось, сохатый & буур & $\begin{array}{c}\text { пулан / пылан / } \\
\text { пулун / план } \\
\end{array}$ & - & улуг-ањ \\
\hline лосиха & булан / иниг & інек / тізі пулан & булан & Иніғ \\
\hline
\end{tabular}

Сыын 'марал' - один из крупных и почитаемых животных тайги. По обычаю тувинцев прямое название сыын 'марал' - табу, вместо него используют эвфемизм сарыг-аң досл. 'желтый зверь'. Данный эвфемизм произошел от окраса животного. Лексема идентичная «желтому зверю» в тофаларском языке используется как общее название марала сарыг-ан (Рассадин, 2005: 84).

Форма sy:n и семантика слова 'самец марала’ для исследуемых языков является общей, вторичный долгий гласный в слове сыын появился в результате выпадения согласного [r] в интервокальной позиции (Сравнительно-историческая ..., 2001: 153).

Названия тув. мыйгак / хак. муйгах / алт. мыйгак / тоф. мыйғақ 'маралуха' - это фонетические варианты одного и того же термина, являются общим названием самки марала.

Чөлеге ‘большой марал' - данное название имеется в тоджинском диалекте тувинского языка и лексема чөлөгө 'матерый бык изюбря’ зафиксирован в тофаларском языке, территориально находящемся на другой стороне одной и той же тайги между Тоджинским районом Тувы и Тофаларией. В остальных исследуемых языках данное название не встречается.

Лексема сарадак ‘годовалый марал', по мнению некоторых ученых, встречается только в некоторых тюркских языках. Так, в работе В. А. Боргоякова отмечается, что данная лексема не известна большинству тюркских языков и представляется саяно-алтайским регионализмом неизвестного происхождения: (чаще ‘самка'), хак. сарадах ‘двухгодовалый теленок марала', алт. сарадак 'двухлетний бычок', ‘однолетний марал, мараленок’ (Боргояков, 2001: 25). В данной лексеме можно выделить основу сар или capb, что может означать ‘желтый, бледный’ + am ‘лошадь, конь'. Возможно, что последние три названия являются отголосками табуирования названий промысловых животных (там же: 26). А в тофаларском языке данное название не было выявлено.

В. А. Боргояков также отмечает, что в хакасском языке лексемы для названия самца и самки лося также отсутствуют. В качестве таких терминов применяются аналитические образования с использованием определений тізі 'самка', інек 'корова', іргек 'самеu', пуга ‘бык'. Автор также выделяет, что в представлении современных носителей хакасского языка слова інек и пуга ассоциируются с домашним скотом, и нет каких-либо оснований рассматривать их первичность в качестве половозрастных терминов диких животных, по крайней мере, в свете данных хакасского языка (там же: 23).

В современных тюркских языках лексема оглах выступает как возрастной термин козленка (в разных пределах - до полугода, до года) чаще домашней, но также и дикой козы. Тюркская праформа рассматриваемого слова оглах, которую связывают с огул 'сын' (огул + ax > оглах), ср.: оглан 'мальчик', 'юноша’ (Щербак, 1961: 119). Есть другое мнение, возводящее оглах к глаголу огыла-, сохранившемуся именно в хакасском: огла- 'кричать, галдеть (о детях)', 'в связи с чем оглах видится как «блеющий», «мекающий» (Сравнительно-историческая ..., 2001: 430). 
Слово булан 'самка лося’ встречается в тувинском и алтайском языках. В тоджинском диалекте тувинского языка для обозначения самки лося используется лексема иниг, подобный вариант имеется в тофаларском иніғ. В хакасском інек / тізі пулан, переводится как 'корова / самка-лось'.

Отсюда можно сделать вывод, что в сравниваемых языках встречаются значительное количество одинаковых названий парнокопытных диких животных. В тувинском и тофаларском языках преобладают одинаковые наименования зверей в связи с тем, что их носители живут в близлежащих таежных местностях, занимаясь в основном одинаковым видом хозяйственной деятельности - охотой. Следует отметить, что указанные в таблице виды животных для народов Саяно-Алтая являются наиболее значимыми, т. к. шкура, которую использовали для хозяйственных нужд самих охотников и для сдачи в пушное производство, обрабатывалась легко, а мясо получалось много, оно считалось полезным и лечебным, употреблялось и самими охотниками, их семьями, и сдавалось в организации общественного питания.

\section{Наименования хищных животных}

Во все времена народы Саяно-Алтая на хищников особо не охотились в связи с тем, что их мясо в еду не употреблялось, за исключением медведя и дикого кабана. В тувинском языке представителей данной группы животных называют тув. араатан аңнар - букв. 'хищные звери' как поедающие других животных, плотоядные животные и как кровожадные, лютые, свирепые (Тувинско-русский ... , 1968: 443).

\begin{tabular}{|c|c|c|c|c|}
\hline $\begin{array}{c}\text { Термины на русском } \\
\text { языке }\end{array}$ & Тувинский язык & Хакасский язык & Алтайский язык & Тофаларский язык \\
\hline медведь & $\begin{array}{c}\text { адыг / ире / ирей* } \\
\text { (букв. дедушка)/ } \\
\text { чоорганныг* } \\
\text { (букв. с одеялом) / чер } \\
\text { кулактыг* } \\
\text { (букв. с земляным } \\
\text { ухом) } \\
\end{array}$ & $\begin{array}{c}\text { аба / аға* } \\
\text { (букв. дедушка)/ } \\
\text { чоорһаннығ" } \\
\text { (букв. с одеялом) / } \\
\text { чир хулах } \\
\text { (букв. земляное } \\
\text { ухо) } \\
\end{array}$ & aŭy & $\begin{array}{c}\text { иресі ањ } \\
\text { (букв. старик зверь) } \\
\text { / ире, ире-ан, ирей } \\
\text { (букв. дедушка, } \\
\text { дедушка-зверь)/ } \\
\text { чоорһанныг* } \\
\text { (букв. с одеялом) }\end{array}$ \\
\hline медведь-самец & эр адыг & $\begin{array}{l}\text { ӱңес / ӱгес / апчах } \\
\text { (букв. мужик) }\end{array}$ & 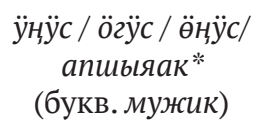 & $\begin{array}{c}\text { ашияқ-аң* } \\
\text { (букв. мужик-зверь) }\end{array}$ \\
\hline медведица & ээщ & инес / и:с & ээщ & ээщ / энэ \\
\hline $\begin{array}{c}\text { самый большой } \\
\text { медведь }\end{array}$ & даг-иргек & - & - & ивриек \\
\hline $\begin{array}{c}\text { двухгодовалый } \\
\text { медведь }\end{array}$ & тодж. диал. чарынды & чарғын & - & чарынды \\
\hline волк & $\begin{array}{c}\text { бөру / узун } \\
\text { кудуруктуг* (букв. с } \\
\text { длинным хвостом) } \\
\text { / тайга ыды * (букв. } \\
\text { собака тайги) }\end{array}$ & 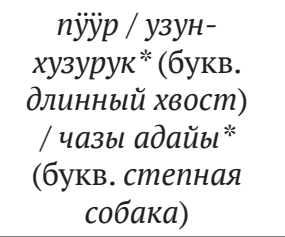 & бӫрӥ & $\begin{array}{c}\text { бөру / кудуруқтуғ* } \\
\text { (букв. с хвостом) } \\
\text { / дағ ыътын (букв. } \\
\text { горный пес) }\end{array}$ \\
\hline
\end{tabular}

Прим.: в таблице имеются эвфемизмы, которые используются вместо прямого наименования, отмеченные знаком*. Следует сказать, что в тоджинском диалекте тувинского языка для одного из наименований двухгодовалого медведя употребляется диалектное слово чарынды, которое зафиксировано и в тофаларском.

Древней религией тюркских народов Саяно-Алтая был шаманизм, сутью которого было поклонение духам. Исходя из соблюдения данной религии тюркские народы Саяно-Алтая в наименовании диких животных используют немало эвфемизмов, которые указаны в таблице. Эвфемизмы (от греч. 
euphēmismos, от eu - хорошо и phēmi - говорю) - эмоционально нейтральные слова или выражения, употребляемые вместо синонимичных им слов или выражений, представляющих говорящему неприличными, грубыми и нетактичными... Ими заменяются также табуированные названия, архаичные (рус. «хозяин» вместо «медведь») (Лингвистический словарь ..., 1990: 590). Медведь - в лит. тув. адыг, лит. хак. аба, лит. алт. айу - это фонетические варианты одного и того же термина, также являются общим названием медведя, а внизу каждого столбца указаны их эвфемизмы.

В тофаларском языке самой лексемы адыг и его вариантов не выявлено, но были зафиксированы ряд других эвфемистических названий, таких как иресі аң 'дедушка-зверь', ашияқ-аң 'мужик-зверь', подобно тувинским эвфемизмам.

Эвфемизмы волка со значением ‘с длинным хвостом’ и ‘собака' встречаются во всех рассматриваемых языках, кроме алтайского. Отметим, что в тувинском языке эвфемизм со значением 'собака' используется в тоджинском диалекте тувинского языка, тайга ыљы букв. 'собака тайги', в хакасском языке данный эвфемизм используется в значении чазы адайы букв. 'степная собака', в тофаларском языке в даг ыъты букв. 'горный пес'. Указанные варианты эвфемизмов подтверждают, где и в какой местности проживает тот или иной народ.

Следовательно, в лексико-семантической группе «Названия хищных животных» встречается большое количество табуированных наименований, вместо которых употребляются их эвфемизмы. Основной причиной считается страх произносить прямое наименование зверя.

\section{Наименования мелких зверей}

Издавна народы Саяно-Алтая пушнину сдавали или обменивали на товар, в связи с чем, охота на мелких зверей велась в специально установленные сезоны.

\begin{tabular}{|c|c|c|c|c|}
\hline $\begin{array}{c}\text { Термины на русском } \\
\text { языке }\end{array}$ & Тувинский язык & Хакасский язык & Алтайский язык & Тофаларский язык \\
\hline \multirow[b]{2}{*}{ соболь } & \multirow{2}{*}{$\begin{array}{c}\text { киш / алды / } \\
\text { чараш-аң* } \\
\text { (букв. красивый } \\
\text { зверь) }\end{array}$} & албыга & киш / албаа & \multirow{2}{*}{$\begin{array}{c}\text { алды / улуг діиң } \\
\text { чарачаң */ (букв. } \\
\text { маленький зверь) }\end{array}$} \\
\hline & & - & - & \\
\hline белка & дииң / сырбык & тиин / сарбах & тийиң & діиң \\
\hline заяц & $\begin{array}{c}\text { кодан / койгун / } \\
\text { тоолай }\end{array}$ & $\begin{array}{c}\text { хозан / табысхан } \\
\text { тоолай }\end{array}$ & койон & hodan \\
\hline суслик & өрге & ӧрке & ӧркӧ & өрге \\
\hline сурок & тарбаган & тарбаган & $\begin{array}{c}\text { тарбаган / } \\
\text { тарбаан }\end{array}$ & - \\
\hline
\end{tabular}

Интересна среди наименований мелких зверей лексема киш 'соболь', об этимологии которой имеются разные мнения. Некоторые исследователи считают, что данное слово тюркское, так как тюркский корень имеет алтайский прототип kil'u ‘мелкий пушной зверь' (Сравнительно-историческая ... , 2001: 163). Другие ученые считают его заимствованием из самодийских языков (Вайнштейн, 1972: 200; Ибрагимов, 1975: 140; Попов, 1968: 73). В тувинском литературном языке употребляется слово киш, в других сравниваемых языках используется лексема тоф. алды / алт. албаa / хак. албыга. Отметим, что в тоджинском диалекте тувинского языка используется диалектное наименование соболя $a л \partial b$.

Толкование эвфемизма в тув. чараш-аң букв. 'красивый зверь', в тоф. чарацаң букв. 'маленький зверь’ разные, хотя по произношению почти одинаковые. Можно предположить, что живущие рядом народы могли заимствовать данное название друг у друга, но значения этих наименований в каждом языке остались разные. В алтайском и хакасском языках подобных наименований мелких зверей не выявлено. 
По данным информантов ${ }^{1}$, мелкие звери у тувинцев основными объектами охоты не являются, так как их мясо не используют в пищу, их добывают только из-за пушнины. Надо также отметить, что на них охотились начинающие охотники, чтобы оттачивать свое мастерство 2 .

\section{Наименования птиц}

Охота на птиц у разных народов Саяно-Алтая также была издревле. Считалось, что мясо птиц очень вкусное и питательное, даже - лечебное.

Во время окотной кампании на диких животных с детенышами запрещается охотиться и в это время объектом охоты для них становятся птицы. Этот вид охоты у тувинцев называют куштаар лит. ‘охотиться на птицу’ (Тувинско-русский ..., 1968: 268).

Общее наименование птицы у народов Саяно-Алтая: тув. куш (там же: 267), алт. куш (Алтайскорусский ..., 2018: 412), хак. хус (Хакасско-русский ..., 1953: 294), тоф. уъһяр чүме (Рассадин, 2005: 247).

\begin{tabular}{|c|c|c|c|c|}
\hline Термины на русском языке & Тувинский язык & Хакасский язык & Алтайский язык & Тофаларский язык \\
\hline глухарь & кара-куш & харасабан & чай & кара-кувш \\
\hline копалуха, глухарка & $\begin{array}{c}\text { дижилик / } \\
\text { дүжүлүк / } \\
\text { дигилик }\end{array}$ & силей & - & $\begin{array}{c}\text { сарыг-бориика, } \\
\text { сарыг-кувш }\end{array}$ \\
\hline тетерев & күртү & $\begin{array}{c}\text { кӱркӥ / хара кӱркӥ / } \\
\text { сарыг курркӱ }\end{array}$ & кёртӥк & hүгртү \\
\hline рябчик & күшкүл & CblM & сымда & үвшпүл \\
\hline куропатка & торлаа & торланъа & агуна & haan \\
\hline
\end{tabular}

Данные таблицы показывают нам, что название тув. кара-куш 'глухарь' букв. ‘черная птица’ / хак. харасабан / хара сабан - 'глухарь (самец)' (Хакасско-русский ..., 2006: 421) / тоф. кара-куъш букв. 'черная птица’ - во всех языках, кроме алтайского, образовано от окраса птицы.

В исследуемых языках термины, обозначающие глухарку, разные: тув. дижилик, дүжүлүк, дигилик / хак. силей / тоф. сарыг-бориика, сарыг-куъш. Обратимся к этимологии слова дижи диал. 'самка' (реализуется в основном как компонент наименований типа дижи бөрү ‘волчица', дижи адыг, дижи хайыракан 'медведица’); дижилик диал. 'самка глухаря, глухарка'; в тере-хольском диалекте тувинского языка словом дишилик называют птенца глухаря (Татаринцев, 2004: 151). По материалам «Сравнительно-исторической грамматики тюркских языков», исходное значение слова определяется как 'особь женского пола (людей, животных)’ (Сравнительно-историческая ..., 2001: 315). В. Я. Бутанаев сопоставляет хакасское название силей с самодийским злей 'тетерев’ (Бутанаев, 1998: 74). В тофаларском языке, можно предположить, что наименование сарыг-бориика, сарыг-куъш произошло от цвета птицы сарыг ‘желтый’

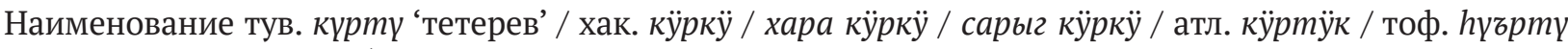
совпадают, но имеются небольшие отличия в произношении. Разные исследователи считают, что данные названия относятся к звукоподражательной основе, подражающей крику индюка курк-курк, и сравнивают с араб., фин. словом kurki 'журавль' (Егоров, 1964). Башкирские названия кдртлдк, кдртлдк 'тетерев’ сравнивают с бур. хура, монг. хур, калм. хур и указывают на вероятность заимствования из монгольских языков, а кор сопоставляет с эвенкийским словом хороки и с монг. хур (Ишбердин, 1970: 14-15, 20); также объясняют, что данные названия созданы звукоподражанием (Гинатулин, 1977: 40).

Название рябчика (лесной птицы семейства тетеревиных с пестрым оперением, см. Ожегов, Шведова, 2010: 2560) в тувинском күшкүл и тофаларском үбшпүл произносятся одинаково, но пишутся по-

\footnotetext{
${ }^{1}$ Кол Нагазы Арган-оолович, 1932 г.р., род. в мест. Ойнаа, Тоджинского района.

${ }^{2}$ Кол Чаш-оол Узун-оолович, 1938 г.р., род. в мест. Серлиг, Тоджинского района.
} 
разному. В хакасском сым и алтайском сымда также созвучны. Ф. Г. Чиспиякова сымна, сынма относит к субстратной лексике (Чиспиякова, 1992: 144).

Тувинское название торлаа 'куропатка', как и в хак. торланба А. Боргояков подразумевает, что слово образовано от хакасского глагола торла- 'шуметь при взлете (о птице)', который восходит к слову тор, основанный на звукоподражании (Боргояков, 2001: 65).

\section{Заключение}

В ходе проведения исследования нами выявлены четыре основных лексико-семантических групп наименований животных.

В лексико-семантической группе «Парнокопытные дикие животные» названия диких животных подразделяются по полу и возрасту, причем они присутствуют во всех исследуемых языках. На парнокопытных животных охотились во все сезоны, мясо и шкура копытных животных представляла большую хозяйственную значимость.

В лексико-семантической группе «Хищные животные» особо следует отметить использование различных эвфемизмов для их наименования, по обычаям предков данные названия являются табуированными лексемами, которые по этикету тюркских народов являются священными запретами. Тувинские охотники всегда остерегаются прямо называть диких животных, особенно хищных. Если кто его нарушит, по мнению предков, их ожидают большие неприятности ${ }^{1}$. Хищники, как в прошлом, так и в настоящее время были и остаются большой опасностью для народа, в связи с чем в языке появились множество эвфемизмов, а сами названия хищных животных табуировались.

В результате проведенного сравнительного анализа лексики охоты тюркских народов Саяно-Алтая авторы пришли к выводу, что в них в основном сохранились древние тюркские корни. Также необходимо отметить выявленные монгольские заимствования, такие как тарбаган, тоолай. Эти монгольские слова представлены лишь в сибирских тюркских языках, длительное время находившихся под монгольским влиянием (Рассадин, Трофимова, Тувшинтогс, 2016: 68-83).

Выяснилось, что табуированные наименования диких животных имеются во всех исследуемых языках. Но в тувинском языке, по имеющимся материалам, больше встречается табуированных наименований в отличие от других исследуемых языков, например, в наименовании адыг 'медведь' зафиксировано более 15 эвфемизмов, причем большая часть данных названий встречаются в тоджинском диалекте тувинского языка, носители которых и в настоящее время занимаются данным видом хозяйственной деятельности. Следует также отметить, что в тоджинском диалекте тувинского языка и в тофаларском языке зафиксировано немало одинаковых наименований, свидетельствующие о территориальной близости и одинаковом образе жизни соседних народов.

В результате проведенного сравнительного анализа охотничьей лексики, в частности названий диких животных и птиц, тюркских языков Саяно-Алтая, пришли к выводу, что выявлены как общие отличительные наименования, например, в названиях парнокопытных, хищников, мелких зверей, птиц. Среди данной лексики имеются и единичные особенные лексемы, которые встречаются в тувинском и тофаларском языках, но не выявлены в других исследуемых языках, например, тув. чөлеге ‘большой марал' / тоф. чөлөгө 'матерый бык изюбря' и др. При проведении анализа зафиксирован интересный факт, что в тофаларском языке самой лексемы адыг 'медведь' не выявлено, хотя были зафиксированы ряд других названий, которых в других языках нами описываются как эвфемизмы, например, иресі аң 'дедушка-зверь', ашияқ-аң 'мужик-зверь', ире 'дедушка'.

Таким образом, можно сделать вывод, что тюркские народы Саяно-Алтая с давних пор населяют таежные районы Сибири и до настоящего времени занимаются охотой и сохраняют данный пласт лексики, кроме алтайского языка, в котором охотничий промысел в прежнем виде утратил свое функционирование, им занимаются единичные охотники-любители.

\footnotetext{
${ }^{1}$ Арнак Чорбаа Алексеевич, 1945 г.р., род. в Тес-Хемском районе.
} 


\section{СПИСОК ЛИТЕРАТУРЫ}

Алтайско-русский словарь (2018) / отв. ред. А. Э. Чумакаев. Горно-Алтайск : БНУ РА «НИИ алтаистики им. С. С. Суразакова». 936 с.

Боргояков, В. А. (2001) Лексика охоты и рыболовства в диалектах хакасского языка : дисс. ... канд. филол. наук. M. 187 c.

Боргояков, М. И. (1981) Источники и истории изучения хакасского языка. Абакан : Хакасское отделение Красноярского книжного изд-ва. 144 с.

Бутанаев, В. Я. (1998) Этническая культура хакасов. Абакан : Изд-во Хакасского государственного университета. 352 с.

Бутанаев, В. Я. (2011) Русско-хакасский словарь (около 15 тыс. слов). Астана ; Петропавловск : Полиграфия. 940 с. Вайнштейн, С. И. (1961) Тувинцы-тоджинцы. М. : Издательство восточной литературы. 217 с.

Вайнштейн, С. И. (1972) Историческая этнография тувинцев. Проблемы кочевого хозяйства. М. : Наука. 314 с.

Гинатулин, М. М. (1977) Мотивация некоторых тюркский названий птиц // Советская тюркология. № 1. С. 38-44.

Даржа, В. А. (2009) Традиционные мужские занятия тувинцев. т. 1: Хозяйство. Охота. Рыбалка. Кызыл : Тувинское книжное издательство. 592 с.

Древнетюркский словарь (1969) / отв. ред. В. М. Наделяев и др. Ленинград : Наука. 676 с.

Дыренкова, Н. П. (1949) Охотничья легенды кумандинцев // Сборник МАЭ / отв. ред. С. П. Толстой. М. ; Л. : Издво АН СССР. Т. XI. 402 с. С. 110-132.

Дыренкова, Н. П. (1963) Тофаларский язык // Тюркологические исследования / отв. ред. А. К. Боровков. М. ; Л. : Изд-во Академии наук СССР. 298 с. С. 18-24.

Егоров, В. Г. (1964) Этимологический словарь чувашского языка. Чебоксары : Чуваш. гос. изд-во. 355 с.

Ибрагимов, К. (1975) Древнетюркские названия животных в лексике современных тюркских языков : автореф. дисс. ... канд. филол. н. М. 27 с. 29 c.

Ишбердин, Э. Ф. (1970) Названия животных и птиц в башкирских говорах : автореф. дисс. ... канд. филол. н. Уфа.

Каксин, А. Д. (2016) О табу и подставных названиях в хантыйском и хакасском языках // Томский журнал лингвистических и антропологических исследований. № 1 (11). С. 45-52.

Катанов Н. Ф. (1903) Опыт исследования урянхайского языка, с указанием главнейших родственных отношений его к другим языкам тюркского народа. Казань : Типография Императорского университета. 1539 с.

Куулар, Е. М. (2018) Наименования диких копытных животных в тувинском и хакасском языках // Мир науки, культуры, образования. № 5 (72). С. 447-449.

Лингвистический энциклопедический словарь (1990) / гл. ред. В. Н. Ярцева. М. : Сов. Экциклопедия. 683 с.

Мусаев, К. М. (1975) Лексика тюркских языков в сравнительном освещении: западнокыпчакская группа. М. : Наука. 359 с.

Назаров, И. И. (2008) Традиционное хозяйство и материальная культура кумандинцев // Культура и традиции коренных народов Северного Алтая / отв. ред. А. В. Малинов. СПб. : Изд. дом Санкт-Петербургского государственного университета. 397 с. С. $125-180$.

Ожегов, С. И., Шведова, Н. Ю. (2010) Толковый словарь русского языка. М. : Оникс. 3423 с.

Патачаков, К. М. (1958) Культура и быт хакасов в свете исторических связей с русским народом (XVIII-XIX). Абакан : Хакасское книжное изд-во.103 с.

Попов, Г. В. (1968) Слова «неизвестного происхождения» якутского языка (сравнительно-историческое исследование). Якутск : Якутское книжное изд-во. 148 с.

Потапов, Л. П. (1929) Охотничьи поверья и обряды у алтайских турков // Культура и письменность Востока / отв. ред. Я. А. Ратгаузер. Баку : Изд-ие Всесоюзного центрального Комитета нового тюркского алфавита. 213 с. C. $123-149$.

Потапов, Л. П. (1935) Разложение родового строя у племен Северного Алтая. М. ; Л. : Гос. соц.-экон. изд-во. 120 с. Потапов, Л. П. (1949) Черты первобытно-общинного строя в охоте северных алтайцев // Сборник МАЭ / отв. ред. С. П. Толстов. М. ; Л. : АН СССР. Т. ХІ. 402 с. С. 5-41.

Потапов, Л. П. (1969) Очерки народного быта тувинцев. М. : Наука. 203 с.

Потапов, Л. П. (1953) Очерки по истории алтайцев. 2-е изд. М. : Изд-во АН СССР. 444 с.

Потапов, Л. П. (2001) Охотничий промысел алтайцев (отражение древнетюркской культуры в традиционном охотничьем промысле алтайцев). СПб. : МАЭ. 168 с. 
Рассадин, В. И. (1971) Фонетика и лексика тофаларского языка. Улан-Удэ : Бурятское книжное издательство. $250 \mathrm{c}$.

Рассадин, В. И. (2000) Хозяйство, быт и культура тофаларов : автореферат дисс.... к. ист. н. Улан-Удэ. 37 с.

Рассадин, В. И. (2005) Словарь тофаларско-русский и русско-тофаларский. СПб. : Дрофа. 295 с.

Рассадин, В. И. (2013) Тюркологические исследования : избранное. Элиста : Изд-во Калмыцкого университета. 214 c.

Рассадин, В. И. (2014) Современный тофаларский язык и его место в системе тюркских языков. Элиста : Изд-во Калмыцкого университета. 218 с.

Рассадин, В. И., Трофимова, С. М., Тувшинтогос Б. (2016) Тюрко-монгольские параллели в составе названий диких копытных животных и охоты на них в монгольских языках // Вестник Бурятского государственного университета / гл. ред. М. В. Бадмаева. Улан-Удэ : Изд-во Бурятского гос. университета. № 2. 254 с. С. 68-83.

Русско-алтайский словарь (1964) / под ред. Н. А. Баскакова. М. : Советская энциклопедия. 457 с.

Салчак, В. С., Монгуш, Б. Б., Баярсайхан, Б. (2010) Тыва аңныыр ажыл-агыйының дугайында чамдык медээлер [(«Некоторые сведения о тувинской охотничьей деятельности»]. Кызыл : Аныяк. 80 с. (На тув. яз.)

Сатлаев, Ф. А. (1969) Кумандинцы Алтайского края : автореф. дисс. ... к. ист. н. Л. 18 с.

Сатлаев, Ф. А. (1974) Кумандинцы: историко-этнографический очерк (XIX - первая четверть XX в.). ГорноАлтайск : Алтайское книжное издательство. 200 с.

Сравнительно-историческая грамматика тюркских языков. Лексика (2001) / под ред. Э. Р. Тенишева. М. : Наука. 822 c.

Сувандии, Н. Д. (2013) Охотничья лексика в тоджинском диалекте тувинского языка // Новые исследования Тувы. № 1. С. $72-78$.

Сувандии, Н. Д. (2016) Табу и эвфемизмы в охотничьей лексике тувинского языка // Филологические науки. Вопросы теории и практики. № 5 (59). С. 138-141.

Сувандии, Н. Д., Куулар, Е. М. (2015) Охотничья лексика в тувинском языке и его диалектах // Казанская наука. № 11. С. 191-193.

Татаринцев, Б. И. (2004) Этимологический словарь тувинского языка. Новосибирск : Наука. Т. III. 440 с.

Толковый словарь тувинского языка (2003) / под ред. Д. А. Монгуша. Новосибирск : Наука. Т. I. 559 с.

Тувинско-русский словарь (1968) : 22000 слов / под ред. Э. Р. Тенишева. М. : Советская энциклопедия. 648 с.

Хакасско-русский словарь (2006) / под ред. О. В. Субраковой. Новосибирск : Наука. 1114 с.

Хакасско-русский словарь (1953) / сост. Н. А. Баскаков, А. И. Инкижекова-Грекул. М. : Гос. изд-во иностр. и нац. слов. 358 с.

Чадамба, З. Б. (1974) Тоджинский диалект тувинского языка. Кызыл : Тувинское книжное изд-во. 136 с.

Чиспиякова, Ф. Г. (1992) Исторические пласты в лексике кондомского диалекта // Хакасская диалектология. Абакан : Хакасский НИИЯЛИ. 224 с. С. 144-156.

Щербак, А. М. (1961) Названия домашних и диких животных в тюркских языках // Историческое развитие лексики тюркских языков / отв. ред. Е. И. Убрятова. М. : Изд-во АН СССР. 468 с. С. 82-172.

Яимова, Н. А. (1985) Табуированная лексика и эвфемизмы в алтайском языке : автореф. дисс. ... канд. филол. н. M. 18 c.

Castren, M. A. (1857) Versuch eine koibalischen und karagassische Sprachlehre nebst Worterverzeichnissen aus den tatarischen Mundarten des Minussinischen Kreises. St.-Pbg : Buchdruckerei der Kaiserlichen Akademie der Wissenschaften. $210 \mathrm{p}$.

Дата поступления: 12.09.2021 2.

\section{REFERENCES}

Altaisko-russkii slovar' [An Altai-Russian Dictionary] (2018) / ed. by A. E. Chumakaev. Gorno-Altaysk, BNU RA Research Institute of Altaistics named after S. S. Surazakov. 936 p. (In Russ.).

Borgoiakov, V. A. (2001) Leksika okhoty i rybolovstva $v$ dialektakh khakasskogo iazyka [The vocabulary of hunting and fishing in the dialects of the Khakass language]: Diss.... Candidate of Philology. Moscow. 187 p. (In Russ.).

Borgoiakov, M. I. (1981) Istochniki i istorii izucheniia khakasskogo iazyka [Sources and histories of the study of the Khakass language]. Abakan, Khakass branch of the Krasnoyarsk Book Publishing House. 144 p. (In Russ.).

Butanaev, V. Ya. (1998) Etnicheskaia kul'tura khakasov [Ethnic culture of the Khakas]. Abakan, Publishing House of Khakass State University. 352 p. (In Russ.). 
Butanaev, V. Ia. (2011) Russko-khakasskii slovar' (okolo 15 tys. slov) [A Russian-Khakass dictionary (c. 15 thousand words)]. Astana; Petropavlovsk, Polygraphy. 940 p. (In Russ.).

Weinstein, S. I. (1961) Tuvintsy-todzhintsy. Istoriko-etnograficheskie ocherki [Tozhu tuvans: historical and ethnographic essays]. Moscow, Nauka. 218 p. (In Russ.).

Weinstein, S. I. (1972) Istoricheskaia etnografiia tuvintsev. Problemy kochevogo khoziaistva [Historical ethnography of Tuvans. Problems of nomadic economy]. Moscow, Nauka. 314 p. (In Russ.).

Ginatulin, M. M. (1977) Motivatsiia nekotorykh tiurkskii nazvanii ptits [Motivation for some Turkic names of birds]. Sovetskaia tiurkologiia, no. 1, pp. 38-44. (In Russ.).

Darzha, V. K. (2009) Traditsionnye muzhskie zaniatiia tuvintsev [Traditional Tuvan male pursuits]. Kyzyl, Tuvan publishing house. 592 p. (In Russ.)

Drevnetiurkskii slovar' [An old Turkic dictionary] (1969) / ed. by V. M. Nadeliaev, D. M. Nasilov, E. R. Tenishev and A. M. Shcherbak. Leningrad, Nauka. 679 p. (In Russ.).

Dyrenkova, N. P. (1949) Okhotnich'ia legendy kumandintsev [Hunting legends of the Kumandins]. In: Sbornik MAE [The MAE collection] / ed. by S. P. Tolstoy. Moscow, Leningrad, Publishing House of the USSR Academy of Sciences. Vol. XI. 402 p. Pp. 110-132. (In Russ.).

Dyrenkova, N. P. (1963) Tofalarskii iazyk [Tofalar language]. In: Tiurkologicheskie issledovaniia [Turkological studies] / ed. A. K. Borovkov. Moscow, Leningrad, Publishing House of the USSR Academy of Sciences. 298 p. Pp. 18-24. (In Russ.).

Egorov, V. G. (1964) Etimologicheskii slovar' chuvashskogo iazyka [Etymological Dictionary of the Chuvash language]. Cheboksary, Chuvash State Publishing House. 355 p. (In Russ.).

Ibragimov, K. (1975) Drevnetiurkskie nazvaniia zhivotnykh v leksike sovremennykh tiurkskikh iazykov [Ancient Turkic names of animals in the vocabulary of modern Turkic languages]: Abstract of Diss.... Candidate of Philology. Moscow. 27 p. (In Russ.).

Ishberdin, E. F. (1970) Nazvaniia zhivotnykh i ptits $v$ bashkirskikh govorakh [Names of animals and birds in Bashkir dialects]: Abstract of Diss.... Candidate of Philology. Ufa. 29 p. (In Russ.).

Kaksin, A. D. (2016) O tabu i podstavnykh nazvaniiakh v khantyiskom i khakasskom iazykakh [On taboos and fake names in the Khanty and Khakass languages]. Tomsk Journal of Linguistic and Anthropological Research, no. 1 (11), pp. 45-52. (In Russ.).

Katanov, N. F. (1903) Opyt izsledovaniia uriankhaiskago iazyka, s ukazaniem glavneishikh rodstvennykh otnoshenii ego $k$ drugim iazykam tiurkskago kornia [An essay on the Uryankhai language, indicating the most important kinship ties between it and the other languages of the Turkic root]. St. Petersburg, Tipo-litografiia Imperatorskogo universiteta. 1600 p. (In Russ.).

Kuular, E. M. (2018) Naimenovaniia dikikh kopytnykh zhivotnykh v tuvinskom i khakasskom iazykakh [Names of wild ungulates in the Tuvan and Khakass languages]. Mir nauki, kul'tury, obrazovaniia, no. 5 (72), pp. 447-449. (In Russ.).

Lingvisticheskii entsiklopedicheskii slovar' [Linguistic Encyclopedic dictionary] (1990) / ed. by V. N. Yartsev. Moscow, Sov. Ektsiklopediia. 683 p. (In Russ.).

Musaev, K. M.(1975) Leksika tiurkskikh iazykov v sravnitel'nom osveshchenii: zapadnokypchakskaia gruppa [The vocabulary of the Turkic languages in comparative coverage: the Western Kypchak group]. Moscow, Nauka. 359 p. (In Russ.).

Nazarov, I. I. (2008) Traditsionnoe khoziaistvo i material'naia kul'tura kumandintsev [Traditional economy and material culture of the Kumandin people]. In: Kul'tura i traditsii korennykh narodov Severnogo Altaia [Culture and traditions of the indigenous peoples of the Northern Altai] / ed. A.V. Malinov. St. Petersburg, Publishing House of St. Petersburg State University. 397 p. Pp. 125-180. (In Russ.).

Ozhegov, S. I. and Shvedova, N. Yu. (2010) Tolkovyi slovar' russkogo iazyka [Explanatory dictionary of the Russian language]. Moscow, Oniks. 3423 p. (In Russ.).

Patachakov, K. M. (1958) Kul'tura i byt khakasov v svete istoricheskikh sviazei s russkim narodom (XVIII-XIX) [Culture and life of the Khakass in the light of their historical ties with the Russian people in the $18^{\text {th }}$ and $19^{\text {th }}$ centuries]. Abakan, Khakass Book Publishing house.103 p. (In Russ.).

Popov, G. V. (1968) Slova «neizvestnogo proiskhozhdeniia» iakutskogo iazyka (sravnitel'no-istoricheskoe issledovanie) [Words of «unknown origin» in the Yakut language: a study in comparative history]. Yakutsk, Yakut Book Publishing House. 148 p. (In Russ.).

Potapov, L. P. (1929) Okhotnich'i pover'ia i obriady u altaiskikh turkov [Hunting beliefs and rituals among the Altai Turks]. In: Kul'tura i pis'mennost' Vostoka [Culture and writing of the East] / ed. by Ya. A. Ratgauser. Baku, Publishing House of the All-Union Central Committee of the New Turkic Alphabet. 213 p. Pp. 123-149. (In Russ.). 
Potapov, L. P. (1935) Razlozhenie rodovogo stroia u plemen Severnogo Altaia [The decay of the tribal system among the tribes of the Northern Altai]. Moscow, Leningrad, Gos. sots.-ekon. izd-vo. 120 p. (In Russ.).

Potapov, L. P. (1949) Cherty pervobytno-obshchinnogo stroia v okhote severnykh altaitsev [Features of the primitive communal system in hunting practices of the Northern Altaians]. In: Sbornik MAE [Collection of MAE] / ed. S. P. Tolstov. Moscow, Leningrad, USSR Academy of Sciences. Vol. XI. 402 p. Pp. 5-41. (In Russ.).

Potapov, L. P. (1969) Ocherki narodnogo byta tuvintsev [The Tuvans: sketches of the folk lifestyle and related household activities]. Moscow, Nauka, GRVL. 402 p. (In Russ.).

Potapov, L. P. (1953) Ocherki po istorii altaitsev [Essays on the history of the Altai people]. Moscow, Leningrad, Izd-vo AN SSSR. 445 p. (In Russ.).

Potapov, L. P. (2001) Okhotnichii promysel altaitsev (otrazhenie drevnetiurkskoi kul'tury $v$ traditsionnom okhotnich'em promysle altaitsev) [Hunting practices of the Altaians: a reflection of the old Turkic culture in the traditional hunting of the Altaians)]. St. Petersburg, MAE. 168 p. (In Russ.).

Rassadin, V. I. (1971) Fonetika i leksika tofalarskogo iazyka [Phonetics and lexics of Tofalar language]. Ulan-Ude, Buriatskoe knizhnoe izdatel'stvo. 252 p. (In Russ.).

Rassadin, V. I. (2000) Khoziaistvo, byt i kul'tura tofalarov [Economy, life and culture of the Tofalars] : Abstract of Diss.... Candidate of History. Ulan-Ude. 37 p. (In Russ.).

Rassadin, V. I. (2005) Slovar' tofalarsko-russkii i russko-tofalarskii [A Tofalar-Russian and Russian-Tofalar dictionary]. St. Petersburg, Drofa. 295 p. (In Russ.).

Rassadin, V. I. (2013) Tiurkologicheskie issledovaniia : izbrannoe [Turkological studies: selected works]. Elista, Publishing House of the Kalmyk University. 214 p. (In Russ.).

Rassadin, V. I. (2014) Sovremennyi tofalarskii yazyk i ego mesto v sisteme tyurkskih yazykov [The Modern Tofalar language and its place in the system of Turkic languages]. Elista, Publishing House of the Kalmyk University. 218 p. (In Russ.).

Rassadin, V. I., Trofimov, S. M., Tuvshintogos B. (2016) Tiurko-mongol'skie paralleli v sostave nazvanii dikikh kopytnykh zhivotnykh i okhoty na nikh v mongol'skikh iazykakh [Turkic-Mongolian parallels in the names of wild ungulates, as well as of practices of hunting them, in Mongolian languages]. Vestnik Buriatskogo gosudarstvennogo universiteta, no. 2, pp. 68-83. (In Russ.).

Russko-altaiskii slovar' [A Russian-Altai Dictionary] (1964) / ed. by N. A. Baskakov. Moscow, Sovetskaia entsiklopediia. 457 p. (In Russ.).

Salchak, V. S., Mongush, B. B. and Baiarsaikhan, B. (2010) Tyva aßnyyr azhyl-agyiynyњ dugaiynda chamdyk medeeler [Some information about Tuvan hunting practices]. Kyzyl, Anyiak. 80 s. (In Tuv.)

Satlaev, F. A. (1969) Kumandintsy Altaiskogo kraia [The Kumandins of the Altai Territory]: Abstract of Diss.... Candidate of History. Leningrad. 18 p. (In Russ.).

Satlaev, F. A. (1974) Kumandintsy: istoriko-etnograficheskii ocherk (XIX - pervaia chetvert' XX v.) [Kumandins: a historical and ethnographic essay (XIX to the first quarter of the XX century)]. Gorno-Altaysk, Altai Book Publishing House. 200 p. (In Russ.).

Sravnitel'no-istoricheskaia grammatika tiurkskikh iazykov. Leksika [A comparative historical grammar of Turkic languages: Vocabulary] (2001) / ed. by E. R. Tenishev. Moscow, Nauka Publ. 800 p. (In Russ.).

Suvandii, N. D. (2013) Okhotnich'ia leksika v todzhinskom dialekte tuvinskogo iazyka [Hunting lexis in the Todzhu dialect of Tuvan language]. New Research of Tuva, no, 1, pp. 72-78. (In Russ.).

Suvandii, N. D. (2016) Tabu i evfemizmy v okhotnich'ei leksike tuvinskogo iazyka [Taboos and euphemisms in the hunting vocabulary of the Tuvan language]. Filologicheskie nauki. Voprosy teorii i praktiki, no. 5 (59), pp. 138-141. (In Russ.).

Suvandii, N. D. and Kuular, E. M. (2015) Okhotnich'ia leksika v tuvinskom iazyke i ego dialektakh [Hunting vocabulary in the Tuvan language and its dialects]. Kazanskaia nauka, no. 11, pp. 191-193. (In Russ.).

Tatarintsev, B. I. (2004) Etimologicheskii slovar' tuvinskogo iazyka [An etymological dictionary of the Tuvan language]. Novosibirsk, Nauka. Vol. III. 440 p. (In Russ.).

Tolkovyi slovar' tuvinskogo yazyka [An explanatory dictionary of the Tuvan language] (2003) / ed. by D. A. Mongush. Novosibirsk, Nauka. Vol. 1. 597 p. (In Russ. and Tuv.). (In Russ.).

Tuvinsko-russkii slovar' [A Tuvan-Russian Dictionary] (1968): c. 22000 words / ed. by E. R. Tenishev. Moscow, Sovetskaia entsiklopediia. 465 p. (In Russ. and Tuv.). 
Khakassko-russkii slovar' - Khakas - orys söstigi [A Khakass-Russian dictionary] (2006) : c. 22000 words / Authors: O. P. Anzhiganova, N. A. Baskakov, M. I. Borgoyakov, A. I. Inkizhekova-Grekul, D. F. Patachakova, O. V. Subrakova, P. E. Beloglazov, Z. E. Kaskarakova, A. S. Kyzlasov, R. D. Sunchugashev and M. D. Chertykova; ed. by O. V. Subrakova. Novosibirsk, Nauka. 1114 p. (In Russ.).

Khakassko-russkii slovar' [A Khakass-Russian dictionary] (1953) / comp. by N. A. Baskakov and A. I. Inkizhekova-Grekul. Moscow, Gos. izd-vo inostr. i nats. slov. 358 p. (In Russ.).

Chadamba, Z. B. (1974) Todzhinskii dialekt tuvinskogo iazyka [The Todzhu dialect of the Tuvan language]. Kyzyl, Tuvan Book Publishing house. 136 p. (In Russ.).

Chispiiakova, F. G. (1992) Istoricheskie plasty v leksike kondomskogo dialekta [Historical layers in the vocabulary of the Kondom dialect]. In: Khakasskaia dialektologiia [Khakass dialectology]. Abakan, Khakasskii NIIIaLI. 224 p. Pp. $144-156$. (In Russ.).

Shcherbak, A. M. (1961) Nazvaniia domashnikh i dikikh zhivotnykh v tiurkskikh iazykakh [Names of domestic and wild animals in the Turkic languages]. In: Istoricheskoe razvitie leksiki tiurkskikh iazykov [The historical development of the vocabulary of the Turkic languages] / ed. by E. I. Ubriatova. Moscow, AN SSSR Publ. 468 p. Pp. 82-172. (In Russ.).

Yaimova, N. A. (1985) Tabuirovannaia leksika i evfemizmy $v$ altaiskom iazyke [Taboo vocabulary and euphemisms in the Altai language]: Abstract of Diss.... Candidate of Philology. Moscow. 18 p. (In Russ.).

Castren, M. A. (1857) Versuch eine koibalischen und karagassische Sprachlehre nebst Worterverzeichnissen aus den tatarischen Mundarten des Minussinischen Kreises. St. Petersburg, Buchdruckerei der Kaiserlichen Akademie der Wissenschaften. 210 p.

Submission date: 12.09.2021. 